\title{
A Gestão em Cursos de Educação a Distância Via Internet: uma visão a partir dos Fatores Críticos de Sucesso
}

Daniela Rodrigues Cunha Retamal

Orientadora: Patrícia Alejandra Behar

Coorientador: Antonio Carlos Gastaud Maçada

Data de defesa: 23 de novembro de 2009

Esta tese apresentada ao Programa de Pós-Graduação em Informática na Educação (PPGIE), linha de pesquisa ambientes informatizados e ensino a distância, tem como objetivo geral analisar os Fatores críticos de Sucesso (FCS) relacionados com os elementos de gestão em cursos de educação a distância via internet. Como objetivos específicos busca identificar os FCS no gerenciamento dos recursos nos cursos em educação à distância via internet; e propor novos elementos que auxiliem o processo de gestão dos cursos de educação a distância via internet. Os elementos de gestão para a educação a distância (EAD) foram definidos com base na literatura e pela análise conjunta da autora e de especialistas. A partir disto destacam-se os elementos de gestão: qualidade, gerenciamento, infra-estrutura, recursos humanos, recursos financeiros, e modelo pedagógico. Estes elementos utilizados no protocolo do estudo de caso para a identificação dos FCS foram validados com especialistas em EAD e no curso de graduação em administração a distância da Universidade Federal do Rio Grande do Sul (UFRGS). A metodologia da pesquisa é o estudo de caso-múltiplos baseado no curso de graduação em pedagogia - licenciatura (PEAD), e no curso de graduação tecnológica - planejamento e gestão para o desenvolvimento rural (PLAGEDER) da UFRGS. A partir dos resultados obtidos nos estudos de caso constatou-se que alguns dos FCS identificados não estavam associados aos elementos correspondentes. Verificou-se também, que um mesmo FCS está ou pode estar relacionado a mais de um elemento de gestão. Neste sentido, os FCS identificados foram resgatados e reagrupados nas categorias dos elementos de gestão. Estas constatações possibilitaram uma nova reflexão sobre os FCS e os elementos de gestão. A partir do resgate teórico, percebe-se a existência de FCS que, embora não tenham sido identificados na pesquisa, merecem uma atenção especial. Dessa forma, alguns fatores foram incorporados, por estarem relacionados com os novos elementos de gestão da EAD. Assim, apresentam-se os novos elementos para auxiliar o processo de gestão em cursos de educação à distância via internet são: qualidade do ensino, responsabilidade da coordenação do curso, gerenciamento dos recursos, e modelo pedagógico do curso.

Palavras-chave: fatores críticos de sucesso, elementos de gestão; gestão em cursos de educação a distância.

Referência:

RETAMAL, Daniela Rodrigues Cunha. A Gestão em Cursos de Educação a Distância Via Internet: uma visão a partir dos Fatores Críticos de Sucesso - Orientadora: Patrícia Alejandra Behar. Coordenador: Antonio Carlos Gastaud Maçada - 2009. Tese (doutorado) - Programa de Pós-Graduação em Informática na Educação, Centro de Estudos Interdisciplinares em Novas Tecnologias da Educação, Universidade Federal do Rio Grande do Sul, 2009, Porto Alegre. 